\title{
Comparison Between Passive And Semi-Active Suspension System Using Matlab/Simulink
}

\author{
Ankita R. Bhise ${ }^{1}$, Rutuja G. Desai ${ }^{2}$, Mr. R. N. Yerrawar ${ }^{3}$, Dr. A.C. Mitra, \\ ${ }^{4}$ Dr. R. R. Arakerimath ${ }^{5}$ \\ 1,2,4 (Department of Mechanical, MES College of Engineering, Pune) \\ ${ }_{3}^{3}$ (Research scholar, Dept. of Mechanical Engineering, Dr. DYPIET, Primpari, Pune, India) \\ ${ }^{5}$ (Department of Mechanical, G H Raisoni College of Engineering \& Research Pune, India)
}

\begin{abstract}
Suspension system plays an important role in ride comfort and road holding. In this paper, the two degree-of-freedom quarter car model with passive and semi-active suspension system is designed using Matlab/Simulink. The semi-active suspension system is designed with MR damper. The control performance is compared between passive and semi-active suspension system. The results showsthe vehicle response results obtained from step and sine of road input simulations. In conclusion we concluded that semi active system gives $93.9 \%$ and $63.7 \%$ better result for step and Half sine input respectively.
\end{abstract}

Keywords: Bingham model, Passive, Quarter car, Semi-active, Simulink,.

\section{Introduction}

Traditionally automotive suspension system designs have been compromise between the three conflicting criteria's namely the road handling, load carrying capacity and passenger comfort. The suspension system must support the vehicle, provide directional control using handling manoeuvres and provide effective isolation of passengers and load disturbance. Recently the semi-active suspension systems have been researched thoroughly and they provide better results as compared to conventional suspension systems.

Semi-active systems can only change the viscous damping co-efficient of shock absorber and do not add energy to the suspension system. They require less energy to function and are less expensive. Among semiactive control devices, magneto-rheological (MR) dampers are particularly interesting because of the high damping force they can produce with low power requirements (being possible to operate with batteries), simple mechanical design and low production costs.

Magneto-rheological (MR) dampers are semi-active control devices that use MR fluids to produce controllable damping. This project concerns the modeling and control of an MR damper for use in a vehicle suspension in order to improve ride comfort and vehicle stability [1].The MR fluids are the most commonly used fluids in the dampers to achieve variable damping coefficient. It, thus, makes the vibration control more effective in wide spectrum of frequencies which is more desired for the automotive applications. A typical magneto-rheological damper consists of cylinder, piston, electromagnetic coil, and the MR fluid .If the circuit in semi-active suspension system fails it will act as a passive suspension system only. Bingham and Bouc-wen are the parametric models for MR damper.

\section{Passive Suspension System}

Lot of common vehicles today uses passive suspension system to control the dynamics of a vehicle's vertical motion as well as spinning (pitch) and tilting (roll). Passive indicates that the suspension elements cannot provide energy to the suspension system. The passive suspension system limits the motion of the body and wheel by limiting their relative velocities to a rate that gives the required ride comfort. This is achieved by using some type of damping element placed between the body and the wheels of the vehicle, such as hydraulic shock absorber. Properties of the dampers are desired to reduce the vertical body acceleration and to provide good tire-road contact force. That is, for a comfortable ride, it is desirable to limit the body acceleration by using a soft absorber, but this allows more variation in the tire-road contact force that in turn reduces the handling performance. Also, the suspension travel, commonly called the sprung mass (the mass of body and other components supported by suspension system) displacement, limits allowable deflection, which in turn limits the amount of relative velocity of the absorber that can be permitted. By comparison, it is desirable to reduce the relative velocity to improve handling by designing a stiffer or higher rate shock absorber. This stiffness decreases the ride quality performance at the same time increases the body acceleration, detract what is considered being good ride characteristics.

An early design for automobile suspension systems focused on unconstrained fulfilment of results for passive suspension system which shows the desirability of low suspension stiffness, reduced unsprung mass, 
and an better damping ratio for the best controllability. Thus the passive suspension systems, which approach optimal values, had offered an appealing choice for a vehicle suspension system and had been widely used for car. However, the conventional shock absorbers do not provide energy to the suspension system and control only the displacement of the vehicle body and wheel by limiting the sprung and unsprung velocity according to the rate determined by the engineers. Hence, the optimization of a passive suspension system is varied according to the road profiles. Passive suspension system representation diagram is shown in Fig.1[2]

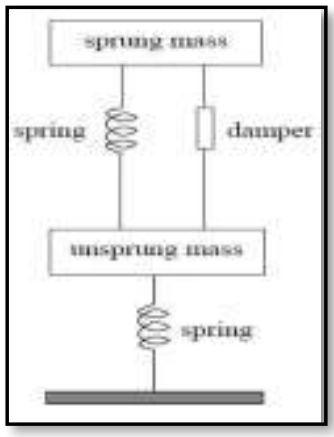

Fig.1: Schematic Diagram of Passive Suspension System

\section{Semi-Active Suspension System}

Semi-active systems can only vary the viscous damping co-efficient of shock absorber and do not add energy to the suspension system. They require less energy to function and are less expensive. Among semiactive control devices, magneto-rheological (MR) dampers are particularly interesting because of the high damping force they can produce with low power (being possible to operate with batteries), simple mechanical design and low production costs.Semi-active suspension system representation diagram is shown in Fig.2[2]

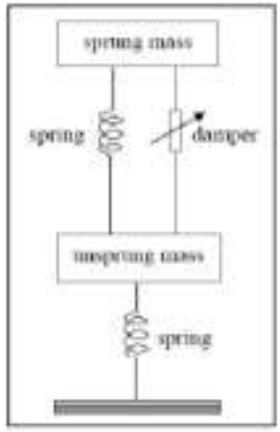

Fig.2: Schematic Diagram of Semi-Active Suspension System

\section{MR Fluid}

In particular, it has been found that MR fluids can be quite promising for vibration reduction applications [3]. MR fluids are slightly identical to electro rheological (ER) fluids and Ferro fluids in composition: all three fluids are a non-colloidal suspension of polarisable particles. While MR and ER fluids usually contain carbonyl iron in the order of a few microns in size, Ferro fluids use nano-meter-sized iron oxide particles. Ferro fluid particles are too small to exhibit any yield strength; instead they tend to be only attracted to and flow toward a magnetic field. MR fluids, on the other hand, exhibit very high yield strength when a field is induced, usually on the order of 20 to 50 times the strength of ER fluids. [4]

With no applied magnetic effects (off state), MR fluids behave with Newtonian-like trait [5]. Applying an external magnetic effect through the fluid activates MR fluids, causing the micron-sized particles to form magnetic dipoles along the lines of magnetic flux, as shown in Fig. 3.[6]

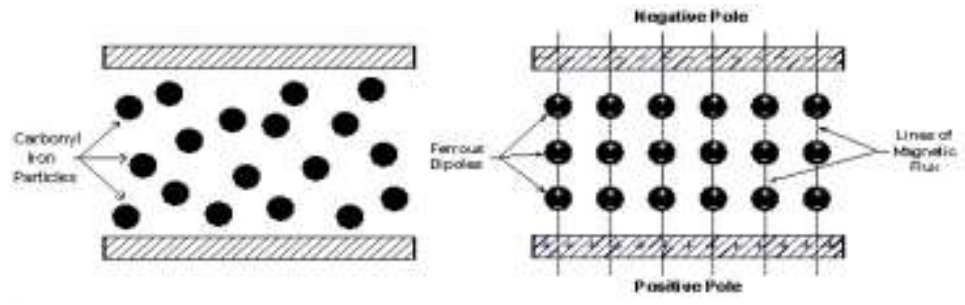


Fig. 3: Mechanism of MR Fluid

The dipoles align parallel to the acquired magnetic flux lines to form chain-like structures of iron particles between the north pole and south pole. The ferrous particles that form each of the chains oppose movement out of their respective flux lines, and the amount of oppose is proportional to the intensity of the applied magnetic field[6].

\section{Suspension Models}

For simulation, the performance of vehicle subjected to random road surface the passive quarter car model as shown in below figures is taken for study.

\subsection{Quarter Car Model With Passive Suspension System:}

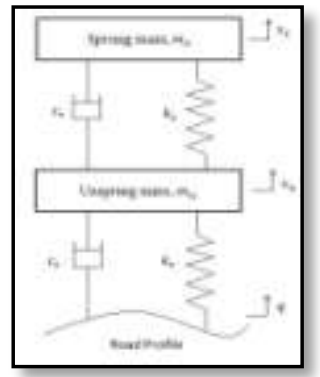

Fig. 4: Quarter car model (Passive Suspension)

The proposed system is 2 DOF quarter car vehicle with passive suspension system. The governing equation of motion these quarter car models are:

$m_{s} \ddot{x} s=-\left[k_{s}\left(x_{s}-x_{u}\right)+c_{s}\left(\dot{x}_{s}-\dot{x}_{u}\right)\right] \ldots \ldots \ldots . . .($ Eq.1)

$m_{u} \ddot{x}_{u}=-\left\{-\left[k_{s}\left(x_{s}-x_{u}\right)+c_{s}\left(\dot{x}_{s}-\dot{x}_{u}\right)\right]+\left[k_{t}\left(x_{u}-q\right)+c_{t}\left(\dot{x}_{u}-\dot{q}\right)\right]\right\}$

Above equations are second-order differential equations of a passive suspension system. Solving this equations of motions is difficult so we can use Matlab/Simulink software. Solving the system and its verification will be done by writing the equations in Matlab using Simulink library blocks.[7]

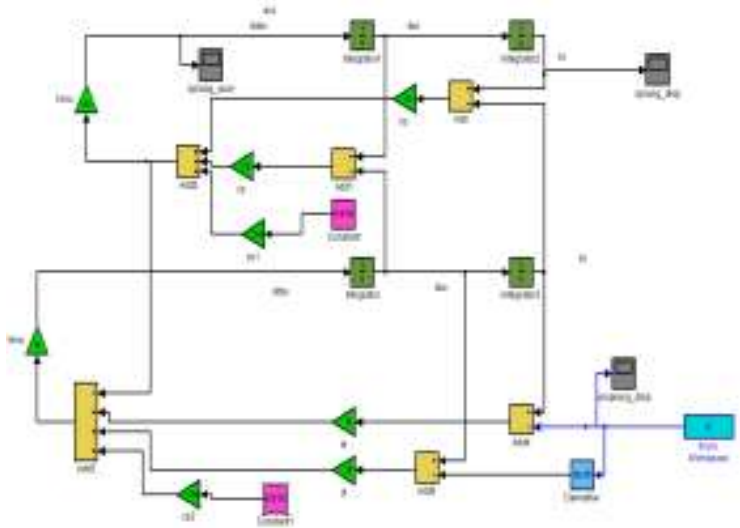

Fig.5 Simulation Model For Passive Suspension

\section{a. Quarter Car Model With Semi Active Suspension System:}

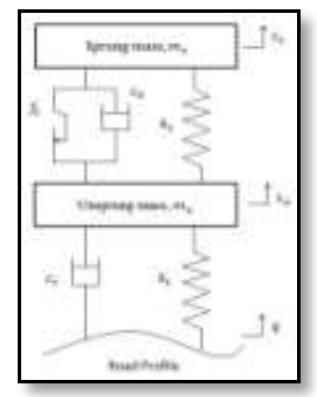


Fig.6: Quarter car Bingham Model

The proposed system is 2 DOF quarter car vehicle with a MR damper. The dynamics of the damper are modelled with the Bingham model i.e. basic model used to describe the behaviour of MR damper. The Bingham model contains the nonlinear behaviour of viscous fluid going through an orifice.

In the rheological structure in Fig.6, on which the Bingham model is based, there is a Coulomb friction element $f c$ placed parallel to the dashpot $c_{0}$. According to Bingham's MR damper model, for non-zero piston velocities, $\dot{x}$ where $f_{c}$ is the frictional force, $c_{0}$ is the viscous damping parameter; $f_{0}$ is the force due to the presence of the accumulator. This simplification in the model results from the assumption that the elasticity replacing the accumulator activity has a low stiffness and linear characteristics.[8]

The Bingham model is a simple model where only two parameters are needed to characterize the MR damper behaviour making the analysis simple. The signum function appearing in the Bingham model results in a non-smooth dynamic behaviour.[4]Signum function returns an integer indicating the sign of a number. The sign of the number argument determines the return value of the sgn function.

- 1 if the corresponding element of $\mathrm{x}$ is greater than 0 .

- $\quad 0$ if the corresponding element of $x$ equals 0 .

- $\quad-1$ if the corresponding element of $x$ is less than 0 .

The governing equations of motion of the quarter car model are:

$f_{a}=f_{c} \operatorname{sgn} \dot{x}+c_{0} \dot{x}+f_{0} \ldots \ldots . . .($ Eq. 3$)$

$m_{s} \ddot{x} s=-\left[k_{s}\left(x_{s}-x_{u}\right)+f_{a}\right] \ldots \ldots \ldots . .($ Eq. 4$)$

$m_{u} \ddot{x} \mathrm{u}=-\left\{-\left[k_{s}\left(x_{s}-x_{u}\right)+f_{a}\right]+\left[k_{t}\left(x_{u}-q\right)+c_{t}(\dot{x} u-\dot{q})\right]\right.$

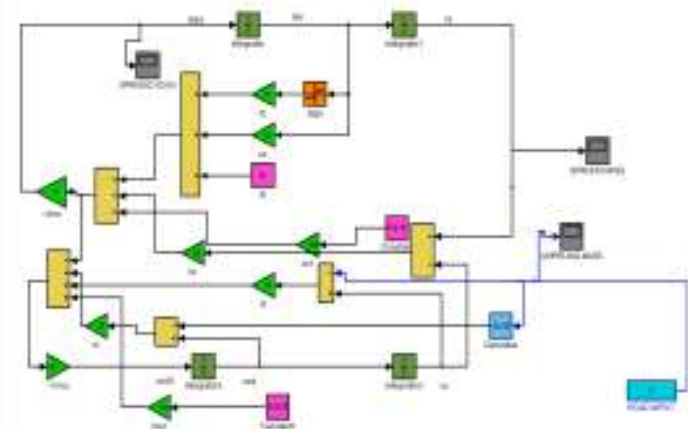

Fig.7 Simulation Model For Semi-active (Bingham) Suspension

\section{Results}

Table 1: Suspension Parameters of Quarter Car Model[9]

\begin{tabular}{|l|l|}
\hline System Parameters & Values \\
\hline Sprung Mass $\left(\mathrm{m}_{\mathrm{s}}\right)$ & $290 \mathrm{Kg}$ \\
\hline Unsprung Mass $\left(\mathrm{m}_{\mathrm{u}}\right)$ & $59 \mathrm{Kg}$ \\
\hline Spring Stiffness $\left(\mathrm{k}_{\mathrm{s}}\right)$ & $16182 \mathrm{~N} / \mathrm{m}$ \\
\hline Damping Coefficient Of System $\left(\mathrm{C}_{\mathrm{s}}\right)$ & $1000 \mathrm{~N}-\mathrm{sec} / \mathrm{m}$ \\
\hline Tire Stiffness $\left(\mathrm{k}_{\mathrm{t}}\right)$ & $190000 \mathrm{~N} / \mathrm{m}$ \\
\hline Damping Coefficient of Tire $\left(\mathrm{C}_{\mathrm{t}}\right)$ & $230 \mathrm{~N}-\mathrm{sec} / \mathrm{m}$ \\
\hline Amplitude & $0.1 \mathrm{~m}$ \\
\hline Velocity & $40 \mathrm{kmph}$ \\
\hline
\end{tabular}

Table 2: Parameters of Bingham Model[10]

\begin{tabular}{|l|l|l|l|}
\hline Current & \multicolumn{4}{|l|}{ Value Of The Parameters } \\
\hline$I(\mathrm{~A})$ & $f_{c}[\mathrm{~N}]$ & $c_{0}[\mathrm{~N}-\mathrm{sec} / \mathrm{m}]$ & $f_{0}[\mathrm{~N}]$ \\
\hline 0.0 & 43.95 & 735.90 & 195.51 \\
\hline 0.4 & 262.13 & 3948.70 & 186.28 \\
\hline
\end{tabular}

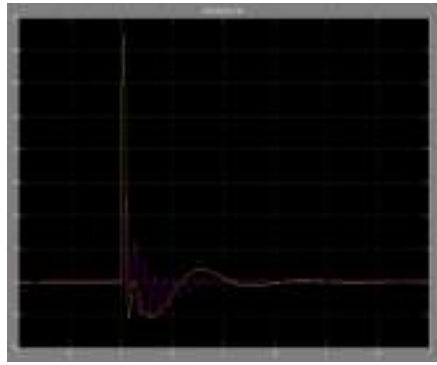


Fig.8: Results of Simulation for Acceleration STEP of Sprung mass

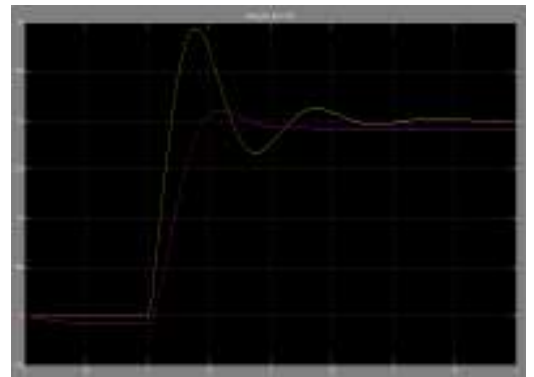

Fig.9: Results of Simulation for Displacement STEP of Sprung mass

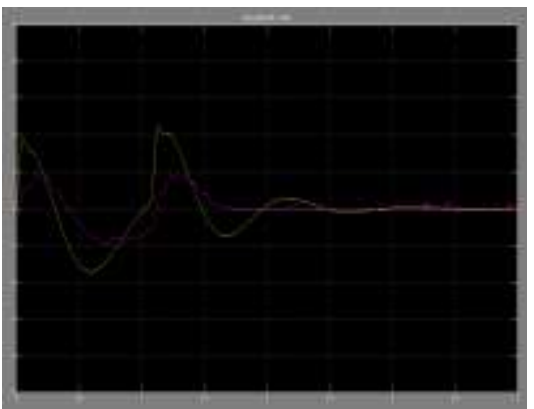

Fig.10 Results of Simulation for Acceleration HALF SINE of Sprung mass

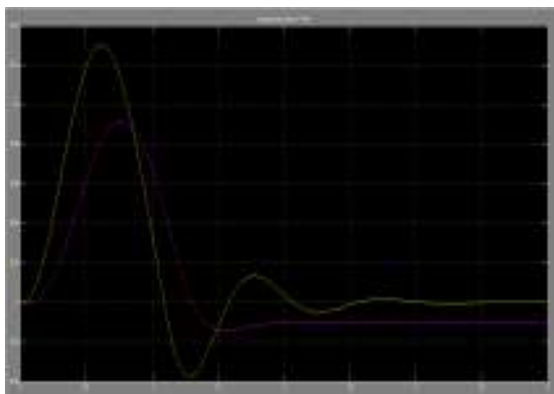

Fig.11: Results of Simulation for Displacement HALF SINE of Sprung mass

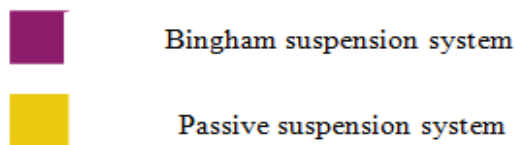

\section{Conclusion}

Table 3: Comparison of RMS Acceleration Response for Step input

\begin{tabular}{|l|l|}
\hline $\begin{array}{l}\text { Suspension System } \\
\text { For 40kmph }\end{array}$ & RMS Sprung Mass Acceleration $\left(\mathbf{m} / \mathbf{s}^{2}\right)$ \\
\hline Passive Suspension System & 1.939 \\
\hline Semi-active Suspension System & 1.052 \\
\hline
\end{tabular}

Table 4: Comparison of RMS Acceleration Response for Half Sine input

\begin{tabular}{|l|l|}
\hline $\begin{array}{l}\text { Suspension System } \\
\text { For 40kmph }\end{array}$ & RMS Sprung Mass Acceleration $\left(\mathbf{m} / \mathbf{s}^{2}\right)$ \\
\hline Passive Suspension System & 1.6370 \\
\hline Semi-active Suspension System & 0.3477 \\
\hline
\end{tabular}

The percentage fluctuation in maximum sprung mass acceleration of semi-active suspension system based on Bingham model is $93.9 \%$ and $63.70 \%$ for Step and Half Sine respectively from passive suspension system. So it shows that semi-active suspension system gives lower value of maximum sprung mass acceleration for above ( Half Sine \& Step) road excitation. There is a new approach of controlling the response of a quarter car vehicle travelling on a rough road with semi active MR damper suspension. The MR damper performance is found to be better as compared to the conventional passive damper system. 


\section{References}

[1]. Hassan Ahmed Metered, "Modeling And Control Of Magneto-rheological Dampers For Vehicle Suspension Systems" A thesis submitted to the University of Manchester for the degree of Doctor of Philosophy in the Faculty of Engineering and Physical Sciences, 2010.

[2]. Ahmad ZaimSolehin Bin CheHasan, "Modelling And Simulation Of Modified Skyhook Control For Semi-Active Suspension" Bachelor Of Engineering, University Malaysia Pahang, 2010.

[3]. H. F.Lam, C. Y.Lai, W. H.Liao," Automobile suspension system with MR Fluid Dampers" The Chinese University of Hong Kong.

[4]. Lord Corporation, "Frequently Asked Questions," Lord Corporation, April, 2003. http://www.mrfluid.com/faqs.htm

[5]. R NYerrawar, Dr.R.RArakerimath, SagarRajendraPatil, PrashantSambhajiWalunj,"Performance Comparison of Semi-Active Suspension and Active Suspension System Using MATLAB/ Simulink".

[6]. John W. Gravatt, "Magneto-Rheological Dampers for Super-sport Motorcycle Applications" Thesis submitted to the Faculty of the Virginia Polytechnic Institute and State University, May 8, 2003.

[7]. Andronic Florin , Manolache-RusuIoan-Cozmin , PătuleanuLiliana, "Passive Suspension Modeling Using Matlab, Quarter Car Model, Input Signal Step Type".

[8]. Mr. Amit A. Hingane, Prof. S. H. Sawant, Prof. S.P. Chavan, Prof. A.P. Shah, "Analysis of Semi active Suspension System with Bingham Model Subjected to Random Road Excitation Using MATLAB/Simulink" IOSR Journal of Mechanical and Civil Engineering (IOSR-JMCE) ISSN: 2278-1684, PP: 01-06

[9]. T. P. Phalke, A. C. Mitra "Comparison of passive and semi-active suspension system by MATLAB SIMULINK for different road profiles" IOSR Journal of Mechanical \& Civil Engineering (IOSR-JMCE) e-ISSN: 2278-1684,p-ISSN: 2320-334X , PP 38-43

[10]. BogdanSapiński, JacekFiluś , " Analysis Of Parametric Models Of MR Linear Damper" Journal Of Theoretical And Applied Mechanics 41, 2, Pp. 215-240, Warsaw 2003 